\title{
Correction to: A new type of [PEI-glycidyl POSS] nanofiltration membrane with enhanced separation and antifouling performance [DOI: 10.1007/s11814-019-0359-y]
}

\author{
Samaneh Bandehali, Abdolreza Moghadassi ${ }^{\dagger}$, Fahime Parvizian, and SayedMohsen Hosseini \\ Department of Chemical Engineering, Faculty of Engineering, Arak University, Arak 38156-8-8349, Iran \\ (Received 11 May 2019 • Revised 2 August 2019 • Accepted 8 August 2019)
}

Unfortunately an error has been occurred on the arrangement of two images (SEM \& AFM) in the results and discussion section during the e.proof reading:

\section{RESULTS AND DISCUSSION}

\section{Characterizations of the Membranes}

The images are related to $\mathrm{M}_{0}$ and $\mathrm{M}_{4}$ samples that must be rearranged and replaced with each other in Fig. 3 and Fig. 5 along with their roughness parameters for them as given in Table 2 . The thick- ness of top layer increased up to $\mathrm{M} 2$ and then decreased again at higher glycidyl POSS ratios. The mean pore size for the membranes was determined by surface analysis through provided images. None of these affect the originality of the articles text.

The authors apologise this mistake.

The original article can be found online at https://doi.org/10.1007/ s11814-019-0359-y

Appendix: The rearranged figures and roughness parameters

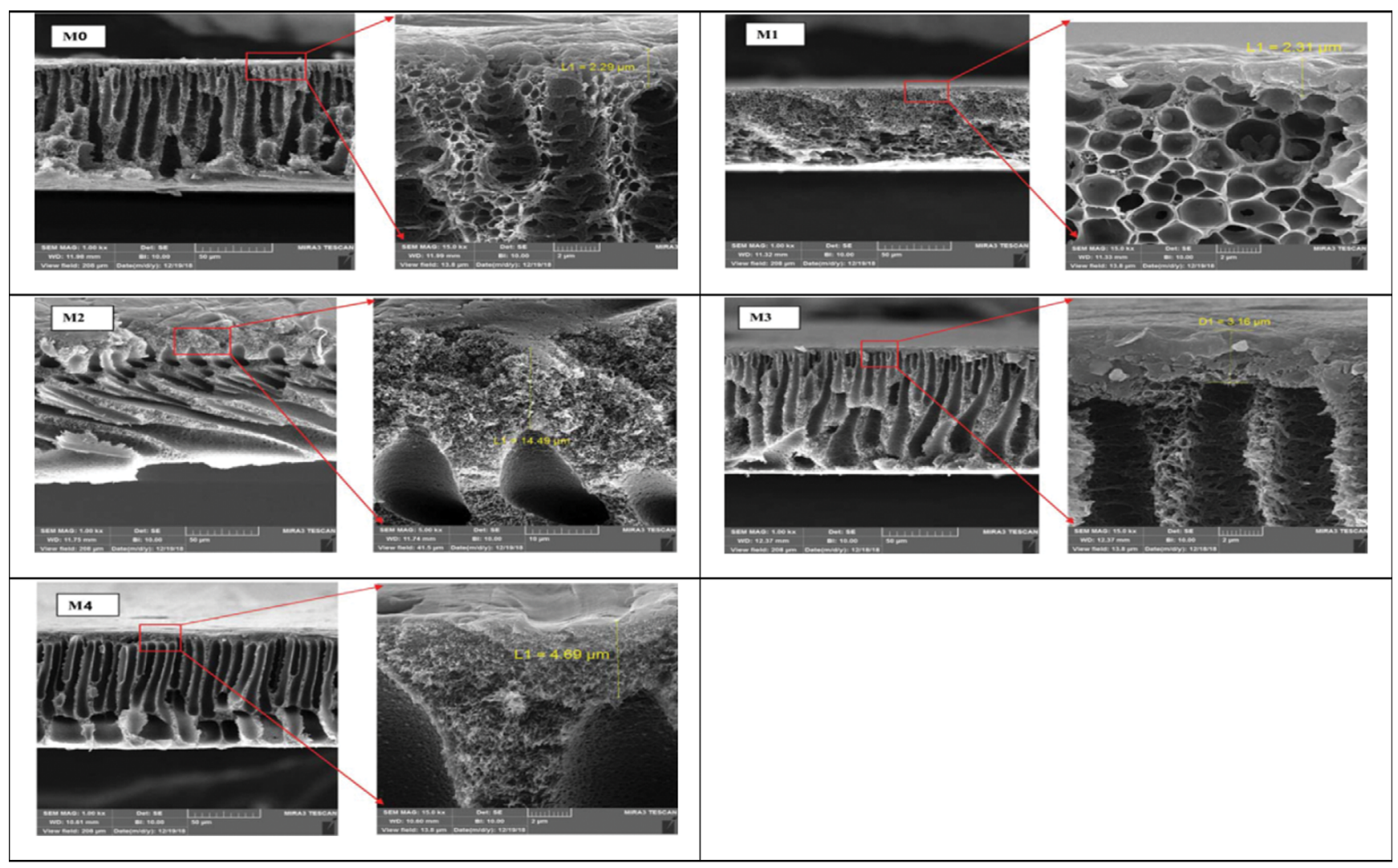

Fig. 3. FESEM cross-section images of prepared membranes.

\footnotetext{
${ }^{\dagger}$ To whom correspondence should be addressed.

E-mail: a-moghadassi@araku.ac.ir

Copyright by The Korean Institute of Chemical Engineers.
} 


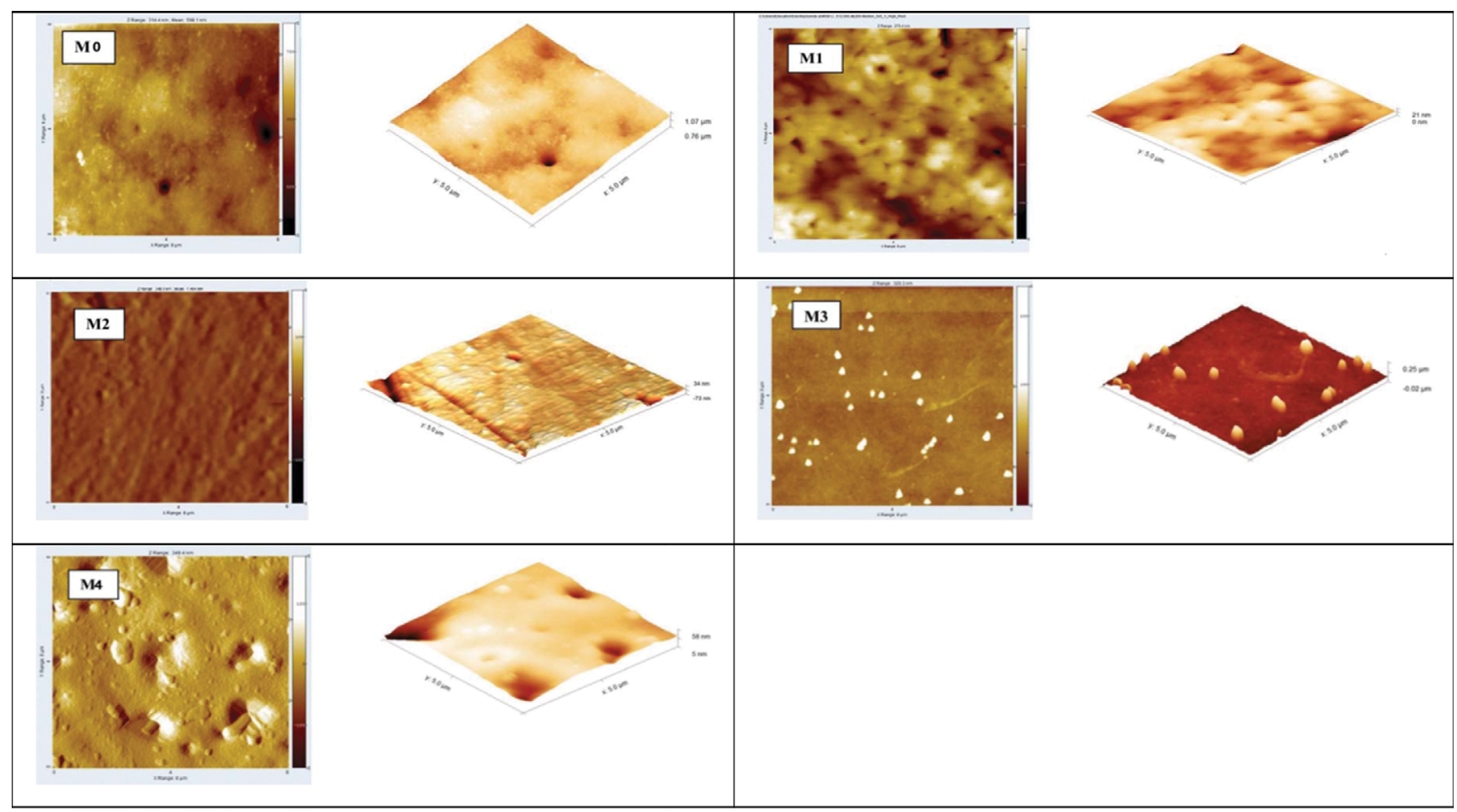

Fig. 5. Three- and two-dimensional AFM images for the fabricated membranes.

Table 2. The roughness parameters for the prepared membranes

\begin{tabular}{ccc}
\hline \hline Sample & $\mathrm{R}_{a}$ & $\mathrm{R}_{q}$ \\
\hline M0 & $19.49 \mathrm{~nm}$ & $23.44 \mathrm{~nm}$ \\
M1 & $27 \mathrm{~nm}$ & $33 \mathrm{~nm}$ \\
M2 & $23 \mathrm{~nm}$ & $30 \mathrm{~nm}$ \\
M3 & $19.17 \mathrm{~nm}$ & $19.1 \mathrm{~nm}$ \\
M4 & $57.7 \mathrm{~nm}$ & $82.8 \mathrm{~nm}$ \\
\hline
\end{tabular}

